\title{
Early death after discharge from emergency departments: analysis of national US insurance claims data
}

\author{
Ziad Obermeyer, ${ }^{1,2,3}$ Brent Cohn, ${ }^{3}$ Michael Wilson, ${ }^{1,3}$ Anupam B Jena,, ${ }^{2}$ David M Cutler ${ }^{4}$
}

'Department of Emergency

Medicine, Harvard Medical

School, Boston, MA 02115, USA

${ }^{2}$ Department of Health Care

Policy, Harvard Medical School,

Boston, MA 02115, USA

${ }^{3}$ Department of Emergency

Medicine, Brigham and

Women's Hospital, Boston, MA

02115, USA

${ }^{4}$ Department of Economics, Harvard University, Cambridge,

MA 02138, USA

Correspondence to: $Z$

Obermeyer zobermeyer@bwh.

harvard.edu

Cite this as: BMJ 2017;356:j239

http://dx.doi.org/10.1136/bmj.j239

Accepted: 23 December 2016

\section{ABSTRACT \\ OBJECTIVE}

To measure incidence of early death after discharge from emergency departments, and explore potential sources of variation in risk by measurable aspects of hospitals and patients.

DESIGN

Retrospective cohort study.

SETTING

Claims data from the US Medicare program, covering visits to an emergency department, 2007-12.

\section{PARTICIPANTS}

Nationally representative $20 \%$ sample of Medicare fee for service beneficiaries. As the focus was on generally healthy people living in the community, patients in nursing facilities, aged $\geq 90$, receiving palliative or hospice care, or with a diagnosis of a life limiting illnesses, either during emergency department visits (for example, myocardial infarction) or in the year before (for example, malignancy) were excluded.

MAIN OUTCOME MEASURE

Death within seven days after discharge from the emergency department, excluding patients transferred or admitted as inpatients.

RESULTS

Among discharged patients, 0.12\% (12375/10 093678, in the $20 \%$ sample over 2007-12) died within seven days, or 10093 per year nationally. Mean age at death was 69 . Leading causes of death on death certificates were atherosclerotic heart disease $(13.6 \%)$, myocardial infarction (10.3\%), and chronic obstructive pulmonary

\section{WHAT IS ALREADY KNOWN ON THIS TOPIC}

Hospitals vary widely in how often emergency department patients are admitted to hospital, but it is unclear how this relates to patient outcomes

Small studies point to non-trivial numbers of patients who die unexpectedly after discharge home from the emergency department, but these studies rely on individual chart reviews or data from single health systems

It is difficult to assess generalizability of these findings or to shed light on how variation across hospitals might shape the quality and safety of emergency care

\section{WHAT THIS STUDY ADDS}

A substantial number of Medicare patients, over 10000 every year, die soon after discharge from US emergency departments, despite relatively young age and no evidence of previous life limiting illnesses

Hospitals with lower admission rates, lower costs, and lower patient volumes had significantly higher rates of death after discharge, despite serving healthier overall patient populations

There is a particular clinical "signature" of discharge diagnoses from emergency departments linked to short term deaths, especially syndromic diagnoses not involving pain, like altered mental status, dyspnea, and malaise and fatigue disease (9.6\%). Some $2.3 \%$ died of narcotic overdose, largely after visits for musculoskeletal problems. Hospitals in the lowest fifth of rates of inpatient admission from the emergency department had the highest rates of early death $(0.27 \%)-3.4$ times higher than hospitals in the highest fifth (0.08\%)-despite the fact that hospitals with low admission rates served healthier populations, as measured by overall seven day mortality among all comers to the emergency department. Small increases in admission rate were linked to large decreases in risk. In multivariate analysis, emergency departments that saw higher volumes of patients (odds ratio $0.84,95 \%$ confidence interval 0.81 to 0.86 ) and those with higher charges for visits $(0.75,0.74$ to 0.77$)$ had significantly fewer deaths. Certain diagnoses were more common among early deaths compared with other emergency department visits: altered mental status (risk ratio 4.4, $95 \%$ confidence interval 3.8 to 5.1), dyspnea (3.1, 2.9 to 3.4), and malaise/fatigue (3.0, 2.9 to 3.7).

\section{CONCLUSIONS}

Every year, a substantial number of Medicare beneficiaries die soon after discharge from emergency departments, despite no diagnosis of a life limiting illnesses recorded in their claims. Further research is needed to explore whether these deaths were preventable.

\section{Introduction}

A growing number of patients visit emergency departments every year: nearly $20 \%$ of the US population each year, ${ }^{1}$ or 400 visits per 1000 population in the UK. ${ }^{2}$ As a result, the decision to admit or discharge a patient from the department is made hundreds of thousands of times a day.

Errors in this decision can take two forms, each with different implications for patients and the healthcare system. One error is avoidable admission to hospitalthat is, admission of patients who could be managed safely and effectively in other settings. This issue has been studied extensively, given its importance for healthcare costs..$^{3-6}$ The other error is avoidable harmthat is, discharge of patients who would have benefitted from further monitoring or treatment as inpatients. This issue has received comparatively little attention, despite its importance for patient safety, outside of studies on specific diagnoses (such as myocardial infarction, ${ }^{7-10}$ subarachnoid hemorrhage ${ }^{11-13}$ ) comprising a small percentage of emergency department populations.

Prior studies have suggested that the deaths of patients who die shortly after discharge from an emergency department could potentially be avoidable if they result from unanticipated deterioration. These efforts have yielded valuable insights into patient characteristics 
linked to early death, such as atypical presentations of acute illnesses ${ }^{1415}$ or injuries in the elderly. ${ }^{16}$ This is timely given increasing attention to the issue of diagnostic error. ${ }^{17-20}$

Existing studies, however, rely on painstaking review of individual charts or data from single health systems. This makes it difficult to assess generalizability of findings or to understand the incidence of early death after discharge nationally. Nor can such studies shed light on how variation across hospitals might shape the quality and safety of emergency care. A key example here is variation in the rate of inpatient admission from an emergency department: while this metric is commonly used to assess the extent of low value hospital care, ${ }^{62122}$ it has not, to our knowledge, been shown to affect patient outcomes.

To fill this gap, we performed the first nationally representative study of early death after discharge from an emergency department in patients living in the community, using US Medicare claims linked to death certificates. Clearly, administrative data cannot offer conclusive evidence on whether such deaths resulted from error. Instead, we hoped to identify clinical and health systems factors linked to potentially unexpected death as a starting point for future study. Understanding of these sentinel events will become increasingly important as policy and quality incentives drive health systems to reduce rates of admission to hospital from the emergency department.

\section{Methods}

\section{Study population and outcome}

From a nationally representative 20\% sample of Medicare claims, we identified fee for service beneficiaries with visits to emergency department in 2007-12.23 We excluded those with nursing facility claims in the month before their visit to focus on active patients living in the community who were attending the department for acute problems. Table $\mathrm{A}$ in appendix 1 provides further details.

Our primary outcome was death within seven days after discharge from emergency departments, as in prior studies. ${ }^{14-162425}$ People admitted as inpatients, transferred out of the department, or discharged to palliative care or a hospice were ineligible for the outcome. In many US emergency departments, patients who require a period of observation for diagnostic testing or monitoring are billed under a specific "observation status.” These patients are subsequently discharged or formally admitted as inpatients, and, for the purposes of this study, we classified patients by this ultimate disposition (that is, admitted or discharged). Observation can happen either in units based in the emergency department or in other hospital departments; as Medicare claims did not distinguish by location, we considered these together. Seven day mortality was chosen based on the assumption that discharged patients were deemed to be at low risk of acute deterioration, such that no immediate testing or treatment was required, and they would be able to return to care if they worsened. Discharged patients should thus resemble generally healthy patients, with similarly low baseline risk of mortality, and early death would be a potentially unanticipated adverse event-though by no means evidence of error or poor care.

\section{Life limiting illnesses}

Of course, in patients with known life limiting illnesses diagnosed in the emergency department or before, death after discharge could have been fully anticipated: poor prognosis can limit utility of admission, or patients might simply prefer to avoid admission. We attempted to exclude such visits in several ways. First, we excluded beneficiaries aged $\geq 90$, who often have incurable conditions $^{26}$ and DNR ("do not resuscitate") or "do not hospitalize" orders. ${ }^{27}$ Second, we excluded those with any claims for hospice or palliative care over the year before visits. Given the fee for service structure of the US healthcare system, providers have a strong incentive to report all patient encounters to insurers; thus it is traditionally assumed ${ }^{28}$ (though difficult to verify) that nearly all care is captured in claims. This assumption applies only to formally coded encounters and would not identify patients who were tacitly rather than formally receiving care oriented to palliation.

As a result, it is likely that such coarse criteria alone are insufficient for identifying patients with a poor prognosis. We thus also broadly excluded discharged patients with conditions that, when diagnosed, implied provider awareness of potentially poor near term prognosis and thus a deliberate decision to discharge despite known risk of mortality. To do so, we convened a panel of three emergency physicians to identify diagnoses indicating life limiting disease: chronic conditions diagnosed in the year before visits-for example, malignancies-and acute conditions diagnosed in the emergency department typically requiring inpatient management-for example, myocardial infarction (see table B in appendix 1). We did not exclude acute conditions for which outpatient management is reasonable in appropriately risk stratified patients-for example, pneumonia. ${ }^{2930}$ Initial inter-rater agreement (к) was 0.81. Disagreements were resolved by consensus.

\section{Descriptive analyses}

After estimating incidence of early death after discharge over the study period, we determined cause of death by linking claims to death certificates. This was last possible in 2008, after which the Medicare administration disallowed linkage. We thus used the subset of 2007-08 visits ( $n=3197209)$ to tabulate cause of early deaths after discharge $(n=4273)$; deaths from 2009-12 were excluded from these analyses. While these data are often inaccurate for assigning specific cause of death, ${ }^{31} 32$ they can be useful for ascertaining broader categories of causes. ${ }^{33}$

\section{Hypothesis testing}

We explored several hypotheses regarding potential sources of variation in early mortality rates.

Temporal variation-We hypothesized that risk of mortality would vary over the year after visits to an department, with the influence of care most apparent 
soon after visits, and the influence of patients' underlying conditions more or less constant over the year. As observed evolution of risk might itself vary as a function of hospitals' admission rates (calculated as fraction of Medicare patients admitted, similar to previous studies that used Medicare data as a proxy for hospital level metrics ${ }^{34-36}$ ), we inspected trends separately by fifth of admission rate. We then calculated weekly mortality for discharged and admitted patients, excluding hospitals with $<100$ visits annually because of unstable rates.

Hospital level variation-We explored additional potential correlates of early mortality at the hospital level, focusing on the first week after discharge. We investigated correlation of risk with urban versus rural location and by academic status based on data from the American Hospital Association. As hospital case mix could affect both early death after discharge and early death after admission, we explored correlations of hospital factors with both.

To more systematically explore factors linked to early death after discharge, we regressed our outcome on two sets of variables: first, hospital level factors including location, annual Medicare volume of the emergency department (that is, by number of Medicare visits to emergency departments by hospital year, calculated from the $100 \%$ inpatient and outpatient files), and the amount charged by the hospital for the visit, as a measure of the complexity and amount of care delivered. Second, we controlled for case mix across hospitals by including demographics, eligibility for Medicaid (a proxy for low income), mean income at postal code level, patient comorbidities over the year before visits, ${ }^{37}$ and fixed effects for year, season, and weekend. As only discharged patients could experience the outcome, we also controlled for hospital admission rate. We clustered standard errors by hospital.

Our first analysis included all patients presenting to emergency departments-that is, both discharged or admitted-to determine which factors, among all patients seen in the department, were associated with early death after discharge? We also present an alternative strategy, in which we included only discharged patients. This answers a different question: among patients whom doctors decided to discharge, which factors are associated with higher risk? This is appealing because only discharged patients are eligible for the outcome; its disadvantage lies in selecting patients for inclusion based on physician judgment, which might vary across hospitals. This limits generalizability to all emergency department patients and also means that departments with higher rates of admission were under-represented, which could bias coefficients. We thus view the first model as preferable.

Diagnostic variation-Finally, we hypothesized that risk of death after discharge would vary across grouped $^{38}$ diagnoses in the emergency department. We calculated risk ratios by diagnosis (primary discharge diagnosis for discharged patients, admitting diagnosis for admitted patients), comparing diagnosis incidence among early deaths after discharge with incidence among all other visits.

\section{Statistical packages}

All analyses were performed in Stata (version 14.0; StataCorp) and R (version 3.2.3; Foundation for Statistical Computing).

\section{Patient involvement}

No patients were involved in setting the research question or the outcome measures, nor were they involved in developing plans for design or implementation of the study. No patients were asked to advise on interpretation or writing up of results. There are no plans to disseminate the results of the research to study participants or the relevant patient community. Our interest in poor short term outcomes after ED visits, however, was informed by patients' priorities, experiences, and preferences.

\section{Results}

\section{Descriptive analyses}

In a nationally representative $20 \%$ sample Medicare beneficiaries, we identified 28086293 visits to an emergency department over 2007-12. We excluded 12091966 (43\%), mostly because of life limiting illnesses diagnosed in the department (such as acute myocardial infarction) or illness diagnosed in the year before the visits (such as malignancy); age $\geq 90$; and non-fee for service (see fig A in appendix 2). Table 1 shows baseline characteristics of remaining visits, of which $37 \%$ involved admission or transfer of the patient.

Among those discharged, 0.12\% (12375/10 093678, in the 20\% sample over 2007-12) died within seven days or 10093 per year nationally. Average age at death was 69; $50.3 \%$ were men, and $80.9 \%$ were white. There were small decreases in rates of early death after discharge from 2007-12, 4-5\% annually (fig B in appendix 2).

Death certificates identified atherosclerotic heart disease (13.6\%), acute myocardial infarction (10.3\%), and chronic obstructive pulmonary disease $(9.6 \%)$ as most common causes of death. Figure 1 shows top causes of death and their antecedent diagnoses on discharge. Narcotic overdose was the eighth most common cause of death (2.3\%); the most common antecedent discharge diagnoses were back pain (15\%) and superficial injuries $(10 \%)$.

\section{Temporal variation}

Figure 2 shows the evolution of weekly risk of mortality over the year after emergency department visits, by fifth of rate of admission from department to inpatient. Among admitted patients, mortality was highest in the first weeks in all hospitals, then declined rapidly. Among discharged patients, by contrast, evolution of risk varied by admission rate. In hospitals in the highest fifth of admission rates, discharged patients had low mortality soon after discharge compared with the remainder of the year. In hospitals in the lowest fifth of admission rates, conversely, discharged patients had higher-not lower-early mortality; rates then declined over the course of the year. 


\begin{tabular}{|c|c|c|c|}
\hline Variable & $\begin{array}{l}\text { Admitted or transferred } \\
(\mathrm{n}=5867649)\end{array}$ & $\begin{array}{l}\text { Discharged } \\
(n=10093678)\end{array}$ & $\begin{array}{l}\text { Difference } \\
\text { (admitted } v \text { discharged) }\end{array}$ \\
\hline \multicolumn{4}{|l|}{ Demographics } \\
\hline Mean age on day of visit (years) & $69.8(69.7$ to 69.8$)$ & $62.2(62.2$ to 62.2$)$ & $7.6(7.5$ to 7.6$)$ \\
\hline Women (\%) & $55.2(55.2$ to 55.2$)$ & $59.5(59.5$ to 59.6$)$ & $-4.3(-4.3$ to -4.3$)$ \\
\hline White $(\%)^{\dagger}$ & $79.7(79.7$ to 79.7$)$ & $76.2(76.2$ to 76.2$)$ & $3.6(3.5$ to 3.6$)$ \\
\hline Rural (\%) & 3.7 (3.7 to 3.8$)$ & $6.7(6.7$ to 6.7$)$ & $-2.9(-3.0$ to -2.9$)$ \\
\hline Mean income $(\$)^{\ddagger}$ & $67389(67368$ to 67410$)$ & 64394 (64379 to 64408$)$ & 2995 (3020 to 2970) \\
\hline \multicolumn{4}{|c|}{ Comorbidities (\% unless marked otherwise) } \\
\hline Mean summed score ${ }^{\S}$ & 3.7 (3.7 to 3.7) & $2.0(2.0$ to 2.0$)$ & $1.7(1.7$ to 1.7$)$ \\
\hline Alcohol abuse & $4.0(3.9$ to 4.0$)$ & $4.6(4.6$ to 4.7$)$ & $-0.7(-0.7$ to -0.7$)$ \\
\hline Any tumor & $40.2(40.1$ to 40.2$)$ & 25.1 (25.1 to 25.1$)$ & $15.0(15.0$ to 15.1$)$ \\
\hline Cardiac arrhythmias & $22.7(22.7$ to 22.7$)$ & 38.7 (38.6 to 38.7$)$ & $-16.0(-16.0$ to -15.9$)$ \\
\hline Chronic pulmonary disease & $39.7(39.7$ to 39.7$)$ & 31.5 (31.4 to 31.5$)$ & $8.2(8.2$ to 8.3$)$ \\
\hline Coagulopathy & 9.9 (9.9 to 9.9) & $5.2(5.1$ to 5.2$)$ & $4.7(4.7$ to 4.8$)$ \\
\hline Complicated diabetes & 21.5 (21.4 to 21.5$)$ & $12.9(12.9$ to 12.9$)$ & $8.5(8.5$ to 8.6$)$ \\
\hline Congestive heart failure & $40.6(40.6$ to 40.7$)$ & $20.0(20.0$ to 20.0$)$ & 20.6 (20.6 to 20.7 ) \\
\hline Deficiency anemias & $40.2(40.1$ to 40.2$)$ & $25.1(25.1$ to 25.1$)$ & $15.0(15.0$ to 15.1$)$ \\
\hline Dementia & 0" & $0^{9}$ & 0"1 \\
\hline Fluid and electrolyte disorders & 36.7 (36.7 to 36.7$)$ & 22.1 (22.1 to 22.1$)$ & $14.6(14.5$ to 14.6$)$ \\
\hline Hemiplegia & $4.2(4.2$ to 4.2$)$ & $2.2(2.2$ to 2.2$)$ & $2.0(1.9$ to 2.0$)$ \\
\hline HIV/AIDS & 0.8 (0.8 to 0.8$)$ & $1.0(1.0$ to 1.0$)$ & $-0.2(-0.2$ to -0.2$)$ \\
\hline Hypertension & $79.3(79.3$ to 79.4$)$ & $68.2(68.2$ to 68.3$)$ & $11.1(11.0$ to 11.1$)$ \\
\hline Liver disease & $5.9(5.9$ to 6.0$)$ & $5.7(5.7$ to 5.8$)$ & $0.2(0.2$ to 0.2$)$ \\
\hline Metastatic cancer & 0 01 & 0" & 0" \\
\hline Peripheral vascular disease & $29.0(29.0$ to 29.1$)$ & $15.7(15.6$ to 15.7$)$ & $13.4(13.3$ to 13.4$)$ \\
\hline Psychosis & $18.0(18.0$ to 18.0$)$ & 22.5 (22.5 to 22.6$)$ & $-4.6(-4.6$ to -4.6$)$ \\
\hline Pulmonary circulation disorders & $29.0(29.1$ to 29.0$)$ & $15.6(15.6$ to 15.7$)$ & $13.4(13.3$ to 13.4$)$ \\
\hline Renal failure & $26.7(26.6$ to 26.7$)$ & $12.6(12.6$ to 12.7$)$ & $13.9(13.9$ to 13.9$)$ \\
\hline Weight loss & $5.9(5.9$ to 5.9$)$ & $2.2(2.2$ to 2.2$)$ & 3.7 (3.7 to 3.7$)$ \\
\hline \multicolumn{4}{|c|}{ Healthcare use in year before visit (\%) } \\
\hline Inpatient admission & $40.1(40.1$ to 40.1$)$ & $18.6(18.6$ to 18.6$)$ & $22.1(22.1$ to 22.1$)$ \\
\hline Emergency department visit & 15.5 (15.5 to 15.6$)$ & 17.9 (17.9 to 18.0$)$ & $-2.4(-2.5$ to -2.4$)$ \\
\hline Clinic visit & 75.5 (75.4 to 75.5$)$ & 75.4 (75.4 to 75.4$)$ & $0.7(0.6$ to 0.7$)$ \\
\hline Hospice & 09 & 09 & 01 \\
\hline Palliative care & 0 "1 & $0^{1}$ & 0 ? \\
\hline
\end{tabular}

*Given large sample size, some $95 \%$ confidence intervals are so small that they are not different from point estimate at reasonable number of significant digits. tDefined based on race variable in Medicare claims.

‡Based on home postal code.

§Combined comorbidity index combining Elixhauser and Charlson scores. ${ }^{37}$

IBy construction, based on exclusion criteria.

Fig 1 | Cause of death and antecedent discharge diagnoses from emergency departments. Association between most common primary discharge diagnoses and most common causes of death from death certificates, for subset of deaths from 2007-08 when death certificate data were available. Thickness of line is proportional to number of beneficiaries with given discharge diagnosis who later died of given cause (see table $D$ in appendix 1 for further details)
Chronic obstructive pulmonary disease $(2.7 \%)$

Congestive heart failure $(0.6 \%)$

Pneumonia (1.0\%)

Chest pain (4.9\%)

Dyspnea (1.9\%)

Abdominal pain (4.3\%) Diabetes complication $(1.0 \%)$ Urinary tract infection $(2.9 \%)$

Superficial injury (5.8\%)

Back pain (4.9\%)

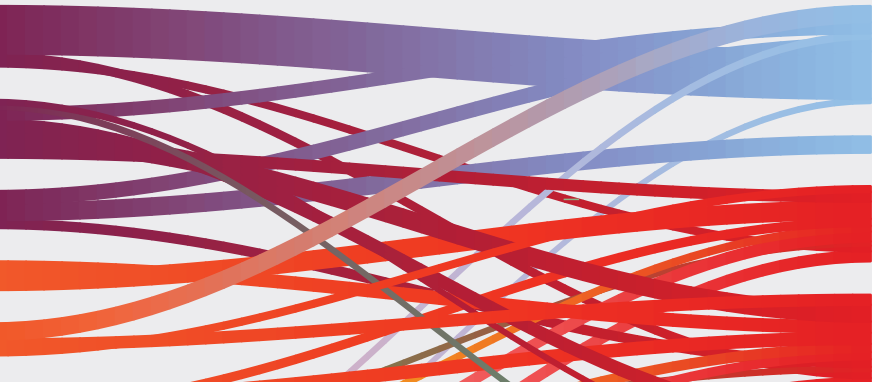
Chronic obstructive pulmonary disease (9.6\%)

Pneumonia (2.6\%)

Acute myocardial infarction (10.3\%)

Atherosclerosis (13.6\%)

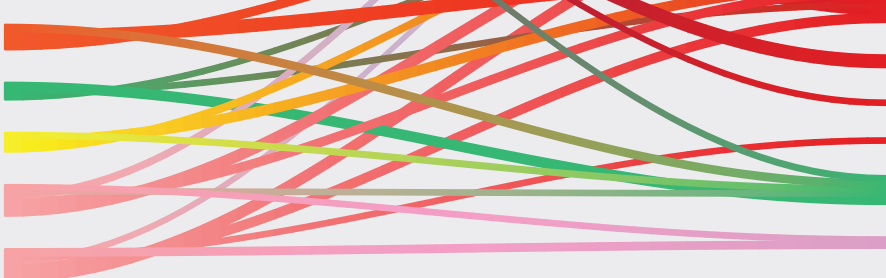

Congestive heart failure (3.1\%)

Cardiomyopathy $(1.9 \%)$

Hypertension

complication (3.0\%)

Diabetes

complication (6.2\%)

Narcotic

overdose (2.3\%) 


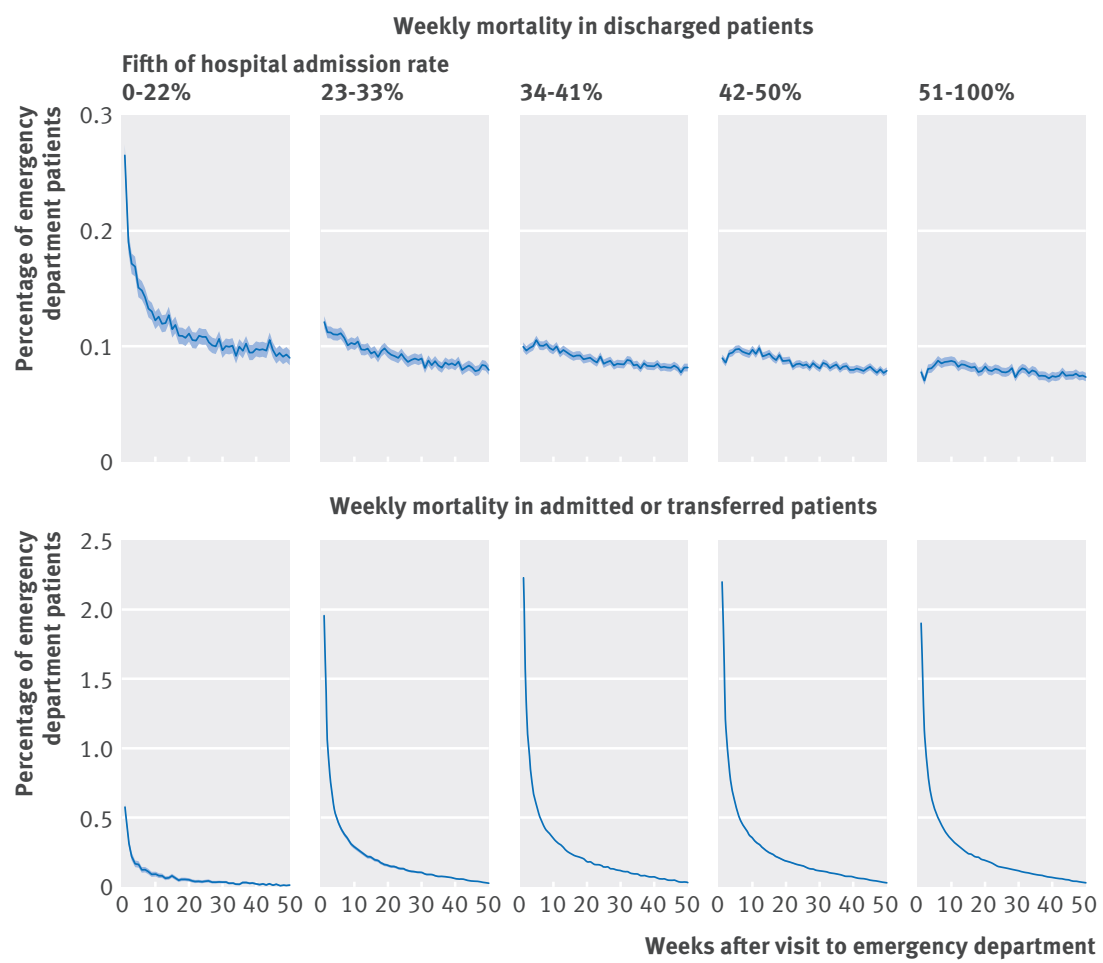

Fig 2 Evolution of weekly mortality risk after emergency department visits. Visit is denoted as week 0 (left). Rates calculated separately, by fifth of rate of emergency department to inpatient admission for Medicare patients, shown in columns from lowest fifth (left) to highest fifth (right). Shaded area around lines shows $95 \%$ confidence interval for mortality rates lowest admission rates had inpatient mortality 3.4 times lower (95\% confidence interval 3.2 to 3.7 ) than the highest. When we combined admitted and discharged patients, overall seven day mortality rates for all comers to emergency departments were $71 \%$ lower in the hospitals with the lowest versus highest admission rates $(0.3$ $v 1.0,95 \%$ confidence interval $69 \%$ to $71 \%$ ). Thus it seems unlikely that baseline population differences alone explained higher early death rates among hospitals with low admission rates.

Table 2 shows factors linked to our outcome via multivariate logistic regression, adjusted for demographics, comorbidities, time trends, and hospital admission rate (table $\mathrm{C}$ in appendix 1 gives the full results). Those who died early were older, more likely to be white and male, and lived in poorer areas. Hospitals with higher Medicare volumes had significantly fewer deaths (odds ratio 0.82, $95 \%$ confidence interval 0.80 to 0.85 ). Patients who visited hospitals with higher emergency department charges were significantly less likely to die $(0.75$, 0.74 to 0.77 ) versus all other visits; this coefficient was reversed $(1.39,1.32$ to 1.36$)$ in model 2 (including only discharged patients), probably reflecting higher complexity of deaths versus other discharged patients. Otherwise, models were similar.

\section{Diagnostic variation}

Figure 4 shows risk ratios for early death after discharge for the 20 most common diagnoses in the emergency department, calculated as the ratio of incidence of diagnosis among deaths versus all other visits (admitted and discharged). Patients with syndromic diagnoses like altered mental status (relative risk 4.4, 95\% confidence interval 3.8 to 5.1), dyspnea (3.1, 2.9 to 3.4), and malaise and fatigue (3.0, 2.9 to 3.7) had the highest risks, followed by diagnoses for which patients at low risk can be managed as outpatients: congestive heart failure $(1.8,1.7$ to 2.0$)$, chronic obstructive pulmonary disease (1.6, 1.5 to 1.8 ), and pneumonia (1.6, 1.5 to 1.8). Interestingly, those with chest pain had among the lowest risks (0.8, 0.8 to 0.9$)$.

\section{Discussion}

In this national analysis, we found that over 10000 Medicare beneficiaries each year died within seven days after being discharged from emergency departments, despite mean age of 69 and no obvious life limiting illnesses. For context, these deaths accounted for $1.7 \%$ of all non-hospice deaths in the Medicare fee for service population annually (see table D in appendix 1). Variability in mortality rates across hospitals was striking: hospitals with low patient volumes and lower admission rates had the highest rates of early death, and small increases in admission rates were linked to large decreases in risk-despite the fact that hospitals with low admission rates served emergency department populations with lower overall near term mortality.

These data should not be viewed as evidence of error. Indeed, some of the variation in outcomes we identified could be linked to the geographic and socioeconomic context of emergency care. First, access to resources 

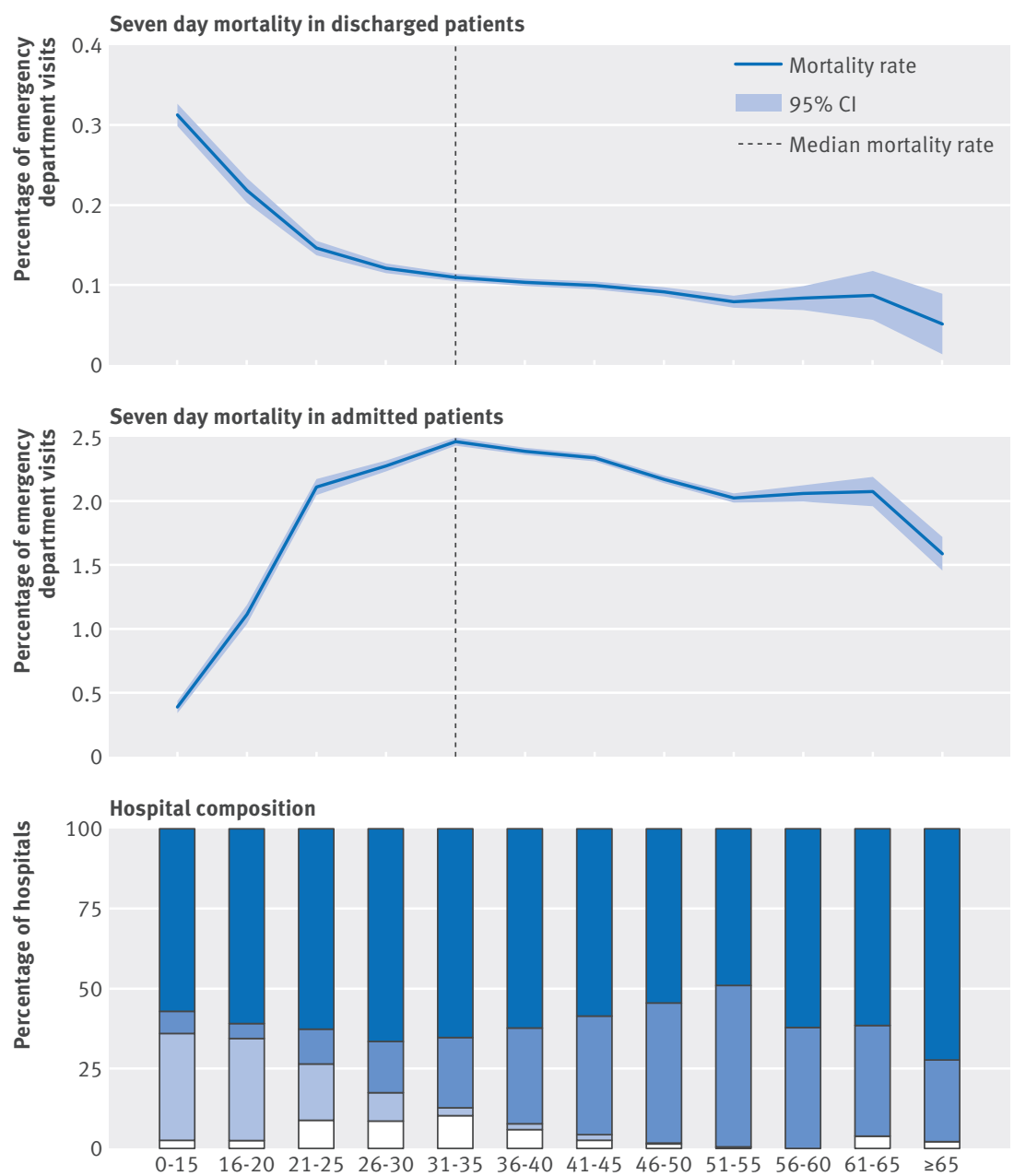

Type

$\square$ (Sub)urban non-academic $\square$ Academic $\square$ Rural CAH $\square$ Rural non-CAH

Fig $3 \mid$ Association between seven day mortality rates and rates of inpatient admission from emergency departments. Rates calculated separately by hospital admission rate. Types of hospital based on data from American Hospital Association. $\mathrm{CAH}=$ critical access varies dramatically across hospitals. For example, to admit patients from the emergency department in hospitals without dedicated internists staffing inpatient beds (hospitalists), emergency physicians must identify willing primary care physicians. These clinicians in turn must take time away from their busy schedules to make rounds on inpatients. The barriers imposed by such arrangements, in addition to a lack of consistent access to specialist consultation or diagnostic resources in the emergency department (such as cardiac ultrasonography, computed tomography), could contribute to worse outcomes in poorer hospitals and patients (T Putnam, personal communication, 2015). Second, patients attending emergency departments with higher mortality after discharge probably differed in important ways that we could not measure. For example, poor beneficiaries eligible for Medicaid can access taxi vouchers to facilitate follow up, but such transportation is generally far less accessible in rural areas, making patients less likely to obtain any scheduled follow-up care (T Putnam, personal communication, 2015). Importantly, while these factors can make sudden death more likely, they do not make it either unavoidable or any less tragic for patients and families.

What are the practical implications of these results? Clearly, not all patients can or should be admitted. But in low volume hospitals with low admission rates, and in patients with specific discharge diagnoses, seven day mortality levels were not trivial. While our study could not determine whether admission would prevent these deaths, it is possible that additional testing or monitoring-whether via admission, monitoring at home, or expedited outpatient follow-up-could have benefitted at least some patients.

This observation perhaps raises more questions than answers and thus suggests several important directions for future research. First, focused clinical audit studies of high risk patients at high risk hospitals could identify opportunities to improve systems of care-rather than to

Table 2 | Results of multivariate logistic regression investigating association between death in seven days after discharge and patient, emergency department, and visit level factors. Model 1 shows results with all patients presenting to departments included in analysis, irrespective of whether they were discharged or admitted. Model 2 includes only discharged patients. Both models control for hospital admission rate, patient comorbidities, and seasonal and temporal factors (see table $C$ in appendix 1). Standard errors were clustered by hospital. Figures are odds ratios with $95 \%$ confidence interval and $P$ values

\begin{tabular}{lll}
$\begin{array}{ll}\text { Variable } \\
\text { Patient factors }\end{array}$ & $\begin{array}{l}\text { Model 1: all patients, admitted } \\
\text { and discharged(n=15961327) }\end{array}$ & $\begin{array}{l}\text { Model 2: discharged } \\
\text { patients only ( } \mathbf{n}=10 \text { 093 678) }\end{array}$ \\
\hline Age & $1.02(1.02$ to 1.02$) ;<0.001$ & $1.03(1.02$ to 1.03$) ;<0.001$ \\
\hline Female & $0.71(0.68$ to 0.74$) ;<0.001$ & $1.39(0.62$ to 0.67$) ;<0.001$ \\
\hline Non-white & $0.90(0.85$ to 0.95$) ;<0.001$ & $0.84(0.80$ to 0.89$) ;<0.001$ \\
\hline Mean income* $(\log )$ & $0.78(0.73$ to 0.83$) ;<0.001$ & $0.72(0.68$ to 0.77$) ;<0.001$ \\
\hline Medicaid dual eligible & $1.01(0.96$ to 1.06$) ; 0.792$ & $1.01(0.97$ to 1.06$) ; 0.607$ \\
\hline Emergency department and visit factors & & $1.39(1.36$ to 1.42$) ;<0.001$ \\
\hline Visit charges $(\log )$ & $0.75(0.74$ to 0.77$) ;<0.001$ & $0.84(0.81$ to 0.87$) ;<0.001$ \\
\hline Annual volume $(\log )$ & $0.82(0.79$ to 0.85$) ;<0.001$ & $1.07(0.96$ to 1.20$) ; 0.226$ \\
\hline Rural location & $1.10(0.98$ to 1.24$) ; 0.10$ &
\end{tabular}


Risk ratio $(95 \% \mathrm{Cl})$

Altered mental status (0.3\%)

Dyspnea (1.3\%)

Malaise/fatigue $(0.7 \%)$

Nausea/vomiting (1.0\%)

Congestive heart failure (3.1\%)

Dehydration (1.4\%)

Chronic obstructive pulmonary disease (9.6\%)

Pneumonia (2.4\%)

Diabetes complication (1.3\%)

Abdominal pain (3.2\%)

Back pain (3.3\%)

Urinary tract infection (2.8\%)

Superficial injuries (3.7\%)

Joint pain (1.4\%)

Syncope (1.4\%)

Medical device complication (1.2\%)

Fracture of arm (1.2\%)

Muscle sprain (3.0\%)

Chest pain $(4.5 \%)$

Cellulitis $(2.4 \%)$

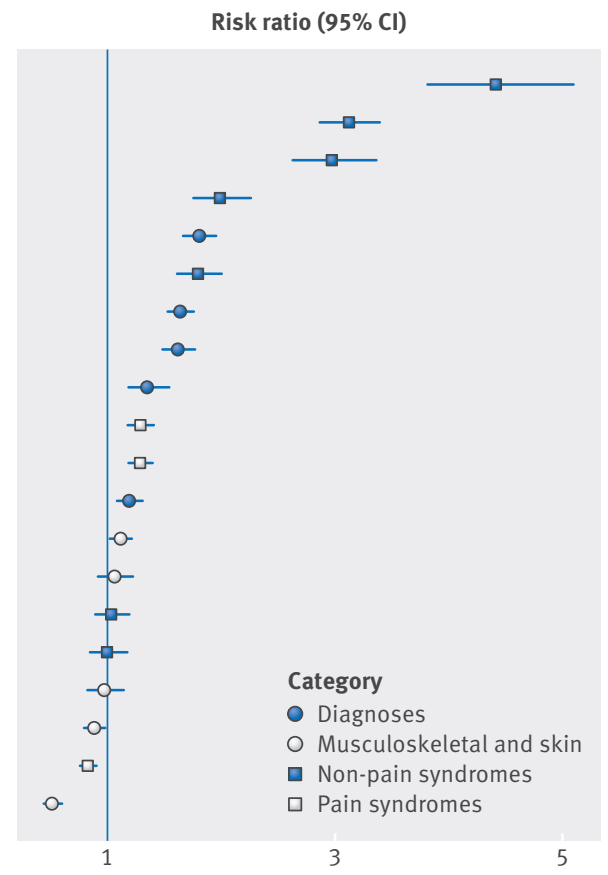

Fig 4 Risk ratios (and 95\% confidence intervals) for early death for 20 most common diagnoses in emergency departments. Incidence of each diagnosis among all patients (admission diagnosis for admitted patients, primary discharge diagnosis for discharged patients) shown in parentheses. Risk ratios calculated as ratio of incidence of diagnosis among early deaths after discharge $v$ frequency among all other emergency department visits (admitted and discharged). Diagnoses grouped into four categories: formal pathophysiological diagnoses of disease (such as pneumonia); syndromic diagnoses, either involving pain (such as chest pain) or not involving pain (such as dyspnea); and diagnoses related to injuries, skin conditions (such as cellulitis) or musculoskeletal pain (such as muscle sprain) measure the benefit and cost of admission for different patient groups. ${ }^{40}$ The role of financial incentives must also be explored: while all patients in this study were insured, supplementary insurance could increase the likelihood of admission and thereby decrease the risk of early death after discharge.

Finally, our results also have implications for ongoing policy efforts to reduce unnecessary admissions from the emergency department. ${ }^{41}$ Unless extreme care is taken with selection of patients, these well intentioned efforts could put patients at risk. Policies designed to reduce overuse, whether in the setting of National Health Service budget constraints in the UK or the Affordable Care Act in the US, could exacerbate this problem. Novel metrics to track patient safety and diagnostic error-which are otherwise under-represented in existing quality measures ${ }^{17}$-are urgently needed to aid policy makers in evaluating how changes in the broader healthcare system impact patient outcomes.

\section{Limitations}

We used Medicare claims because of their broad coverage of US hospitals and the populations they serve. But claims data cannot conclusively identify preventable errors in care. Rather, our aim was to present the first national data on early death after discharge and to identify clinical and health systems factors linked to higher risk. We see this effort as a starting point for future research on patient safety in emergency departments, which has been surprisingly under-researched outside of specific diagnoses comprising a small minority of patients (such as myocardial infarction, stroke, subarachnoid hemorrhage, appendicitis).

We attempted to focus on potentially unexpected deaths by restricting our study to younger generally healthy patients living in the community with good overall prognoses. A particularly difficult task was exclusion of beneficiaries with diagnosed life limiting illnesses, in whom death was not unexpected. As there was, to our knowledge, no prior literature on this topic, we developed a list of ICD codes for this study: acute life threatening conditions diagnosed in the emergency department or chronic conditions diagnosed in the year before visits. While it was based on the judgment of experienced emergency physicians, this list was necessarily subjective. We attempted to be conservative, but some life limiting comorbidities might be omitted; alternatively, excluded diagnoses could be viewed as overly broad. For example, we excluded any beneficiaries with claims indicating any malignancy in the year before emergency department visits because cancer stage cannot be reliably determined from claims ${ }^{42}$; but this might exclude patients with good overall prognoses. Likewise, exclusion of pulmonary embolism might exclude seemingly low risk patients deliberately sent home from emergency departments. Finally, given differences in coding intensity and access to end of life care, patients in less well resourced areas might have been less likely to be excluded by these criteria; this is symptomatic of a broader, and as yet unsolved, problem with risk adjustment in administrative data. ${ }^{43}$ 
Some deaths might have reflected "baseline" mortality after discharge from the emergency department. We view this as unlikely given observed variation in risk of mortality over time and across hospitals. Hospitals with higher admission rates seemed better able to triage high risk patients into hospital admission, rather than discharging them home: discharged patients had lower early mortality rates after visits than over the remainder of the year, while inpatients had higher early mortality. In lower admission rate hospitals, conversely, high risk patients were less likely to be admitted and more likely to be sent home. Such discharged patients had a far higher mortality in the days after visits than subsequently, while inpatients had a far lower early mortality than other hospitals. Together, these trends argue that early death after discharge was not simply a reflection of baseline mortality rates. Interestingly, this also suggests that hospitals with high admission rated do not admit indiscriminately: if high acuity inpatients were diluted with healthy patients who could have been discharged, inpatient mortality would fall, not rise, with admission rate (unless these hospitals were also killing their inpatients at dramatically higher rates).

\section{Conclusion}

Many Medicare beneficiaries die shortly after discharge from emergency departments, despite no obvious life limiting illnesses recorded in their claims. Hospitals with low admission rates and low patient volumes, and patients with high risk diagnoses at discharge, could represent targets for clinical research and quality improvement efforts.

We thank David Peak for participating in the expert panel to classify groups of ICD codes into acute and chronic life limiting diagnoses and for his thoughtful advice on this project; and Tim Putnam for providing extremely valuable insights into emergency care in rural hospitals.

Contributors: ZO designed the study, wrote the manuscript, and obtained funding. BC and ZO performed data analysis. DMC, ABJ, and MW contributed to the design of the study and writing of the manuscript. All authors had full access to all of the data (including statistical reports and tables) in the study and can take responsibility for the integrity of the data and the accuracy of the data analysis. Funding: This research was supported by a grant from the Office of the Director of the National Institutes of Health (DP5 OD012161) to $\mathrm{ZO}$ and a grant from the Laura and John Arnold Foundation. This research was independent from funders. The funder had no role in the study design; in the collection, analysis, and interpretation of data; in the writing of the report; or in the decision to submit the article for publication. The views presented here are those of the authors and not necessarily those of the Laura and John Arnold Foundation, its directors, officers, or staff.

Competing interests: All authors have completed the ICMJE uniform disclosure form at www.icmje.org/coi_disclosure.pdf and declare: no financial relationships with any organizations that might have an interest in the submitted work in the previous three years; no other relationships or activities that could appear to have influenced the submitted work.

Ethical approval: This study was approved by the institutional review boards of Partners HealthCare and the National Bureau of Economic Research.

Data sharing: No additional data available.

Transparency: The lead author affirms that the manuscript is an honest, accurate, and transparent account of the study being reported; that no important aspects of the study have been omitted; and that any discrepancies from the study as planned have been explained

This is an Open Access article distributed in accordance with the Creative Commons Attribution Non Commercial (CC BY-NC 3.0) license, which permits others to distribute, remix, adapt, build upon this work non-commercially, and license their derivative works on different terms, provided the original work is properly cited and the use is non-commercial. See: http://creativecommons.org/licenses/ by-nc/3.0/.

1 Garcia TC, Bernstein AB, Bush MA. Emergency department visitors and visits: who used the emergency room in 2007?NCHS Data Brief 2010;38:1-8. http://www.cdc.gov/nchs/data/databriefs/db38.pdf.

2 Baker C. Accident and Emergency Statistics. House of Commons Library, 2015.

3 Fisher ES, Wennberg JE, Stukel TA, et al. Associations among hospital capacity, utilization, and mortality of US Medicare beneficiaries, controlling for sociodemographic factors. Health Serv Res 2000;34:1351-62.

4 Schuur JD, Venkatesh AK. The growing role of emergency departments in hospital admissions. N Engl J Med 2012;367:391-3. doi:10.1056/ NEJMp1204431.

5 Joynt KE, Gawande AA, Orav EJ, Jha AK. Contribution of preventable acute care spending to total spending for high-cost Medicare patients. JAMA 2013;309:2572-8. doi:10.1001/jama.2013.7103.

6 Venkatesh AK, Dai Y, Ross JS, Schuur JD, Capp R, Krumholz HM. Variation in US hospital emergency department admission rates by clinical condition. Med Care 2015;53:237-44. doi:10.1097/ MLR.0000000000000261.

7 Lee TH, Rouan GW, Weisberg MC, et al. Clinical characteristics and natural history of patients with acute myocardial infarction sent home from the emergency room. Am J Cardiol 1987;60:219-24. doi:10.1016/0002-9149(87)90217-7.

8 Schor S, Behar S, Modan B, Barell V, Drory J, Kariv I. Disposition of presumed coronary patients from an emergency room. A follow-up study. JAMA 1976;236:941-3. doi:10.1001/ jama.1976.03270090035024.

9 Collinson PO, Premachandram S, Hashemi K. Prospective audit of incidence of prognostically important myocardial damage in patients discharged from emergency department. BMJ 2000;320:1702-5. doi:10.1136/bmi.320.7251.1702.

10 Pope JH, Aufderheide TP, Ruthazer R, et al. Missed diagnoses of acute cardiac ischemia in the emergency department. N Engl J Med 2000;342:1163-70. doi:10.1056/NEJM200004203421603.

11 Vermeulen MJ, Schull MJ. Missed diagnosis of subarachnoid hemorrhage in the emergency department. Stroke 2007;38:1216-21. doi:10.1161/01.STR.0000259661.05525.9a.

12 Kowalski RG, Claassen J, Kreiter KT, et al. Initial misdiagnosis and outcome after subarachnoid hemorrhage. JAMA 2004;291:866-9. doi:10.1001/jama.291.7.866.

13 Mayer PL, Awad IA, Todor R, et al. Misdiagnosis of symptomatic cerebral aneurysm. Prevalence and correlation with outcome at four institutions. Stroke 1996;27:1558-63. doi:10.1161/01.STR.27.9.1558.

14 Sklar DP, Crandall CS, Loeliger E, Edmunds K, Paul I, Helitzer DL. Unanticipated death after discharge home from the emergency department. Ann Emerg Med 2007;49:735-45. doi:10.1016/j. annemergmed.2006.11.018

15 Gabayan GZ, Derose SF, Asch SM, et al. Patterns and predictors of short-term death after emergency department discharge. Ann Emerg Med 2011;58:551-558.e2. doi:10.1016/j.annemergmed.2011.07.001.

16 Kefer MP, Hargarten SW, Jentzen J. Death after discharge from the emergency department. Ann Emerg Med 1994:24:1102-7. doi:10.1016/S0196-0644(94)70239-X.

17 Institute of Medicine. Improving Diagnosis in Health Care. National Academies Press, 2015.

18 Wachter RM. Why diagnostic errors don't get any respect--and what can be done about them. Health Aff (Millwood) 2010;29:1605-10. doi:10.1377/hlthaff.2009.0513.

19 Newman-Toker DE, Pronovost PJ. Diagnostic errors--the next frontier for patient safety. JAMA 2009;301:1060-2. doi:10.1001/ jama.2009.249.

20 Singh $\mathrm{H}$. Diagnostic errors: moving beyond 'no respect' and getting ready for prime time. BMJ Qual Saf 2013;22:789-92. doi:10.1136/ bmjqs-2013-002387.

21 Pines JM, Mutter RL, Zocchi MS. Variation in emergency department admission rates across the United States. Med Care Res Rev 2013;70:218-31. doi:10.1177/1077558712470565.

22 Capp R, Ross JS, Fox JP, et al. Hospital variation in risk-standardized hospital admission rates from US EDs among adults. Am J Emerg Med 2014;32:837-43. doi:10.1016/j.ajem.2014.03.033.

23 Research Data Assistance Center (ResDAC) U of M. How to Identify Hospital Claims for Emergency Room Visits in the Medicare Claims Data. http://www.resdac.org/resconnect/articles/144.

24 Gabayan GZ, Sun BC, Asch SM, et al. Qualitative factors in patients who die shortly after emergency department discharge. Acad Emerg Med 2013:20:778-85. doi:10.1111/acem.12181.

25 Gabayan GZ, Gould MK, Weiss RE, et al. Poor Outcomes After Emergency Department Discharge of the Elderly: A Case-Control Study. Ann Emerg Med 2016;68:43-51.e2. doi:10.1016/j. annemergmed.2016.01.007. 
26 Bynum JPW, Rabins PV, Weller W, Niefeld M, Anderson GF, Wu AW. The relationship between a dementia diagnosis, chronic illness, medicare expenditures, and hospital use. I Am Geriatr Soc 2004:52:187-94. doi:10.1111/j.1532-5415.2004.52054.x.

27 Levy CR, Fish R, Kramer A. Do-not-resuscitate and do-not-hospitalize directives of persons admitted to skilled nursing facilities under the Medicare benefit. J Am Geriatr Soc 2005:53:2060-8. doi:10.1111/j.1532-5415.2005.00523.x.

28 Wennberg JE, Roos N, Sola L, Schori A, Jaffe R. Use of claims data systems to evaluate health care outcomes. Mortality and reoperation following prostatectomy. JAMA 1987;257:933-6. doi:10.1001/ jama.1987.03390070053022

29 Fine MJ, Auble TE, Yealy DM, et al. A prediction rule to identify low-risk patients with community-acquired pneumonia. N Engl / Med 1997;336:243-50. doi:10.1056/NEJM199701233360402.

30 Lim WS, van der Eerden MM, Laing R, et al. Defining community acquired pneumonia severity on presentation to hospital: an international derivation and validation study. Thorax 2003;58:377-82. doi:10.1136/thorax.58.5.377.

31 Lauer MS, Blackstone EH, Young JB, Topol El. Cause of death in clinica research: time for a reassessment?] Am Coll Cardiol 1999;34:618-20. doi:10.1016/S0735-1097(99)00250-8

32 Lloyd-Jones DM, Martin DO, Larson MG, Levy D. Accuracy of death certificates for coding coronary heart disease as the cause of death. Ann Intern Med 1998;129:1020-6. doi:10.7326/0003-4819-129-12-199812150-00005

33 Murray CJ, Lopez AD. Global and regional cause-of-death patterns in 1990. Bull World Health Organ 1994;72:447-80

34 Birkmeyer JD, Stukel TA, Siewers AE, Goodney PP, Wennberg DE, Lucas FL. Surgeon volume and operative mortality in the United States. N Engl J Med 2003;349:2117-27. doi:10.1056/NEJMsa035205.
35 Ross JS, Normand S-LT, Wang Y, et al. Hospital volume and 30-day mortality for three common medical conditions. N Engl / Med 2010;362:1110-8. doi:10.1056/NEJMsa0907130.

36 McGrath PD, Wennberg DE, Dickens JD Jr, et al. Relation between operator and hospital volume and outcomes following percutaneous coronary interventions in the era of the coronary stent. JAMA 2000;284:3139-44. doi:10.1001/jama.284.24.3139.

37 Gagne JJ, Glynn RJ, Avorn J, Levin R, Schneeweiss S. A combined comorbidity score predicted mortality in elderly patients better than existing scores. J Clin Epidemiol 2011;64:749-59. doi:10.1016/j. iclinepi.2010.10.004

38 Healthcare Cost and Utilization Project. Clinical Classifications Software for ICD-9-CM. https://www.hcup-us.ahrq.gov/toolssoftware/ ccs/ccs.jsp. 2015.

39 Leape LL. Error in medicine. JAMA 1994;272:1851-7. doi:10.1001/ jama.1994.03520230061039.

40 Doyle J, Graves J, Gruber J, Kleiner S. Measuring returns to hospital care: Evidence from ambulance referral patterns. J Polit Econ 2015;123:170-214. doi:10.1086/677756.

41 Venkatesh AK, Schuur JDA. A “Top Five" list for emergency medicine: policy and research agenda for stewardship to improve the value of emergency care. Am J Emerg Med 2013;31:1520-4. doi:10.1016/j. ajem.2013.07.019.

42 Cooper GS, Yuan Z, Stange KC, Amini SB, Dennis LK, Rimm AA. The utility of Medicare claims data for measuring cancer stage. Med Care 1999;37:706-11. doi:10.1097/00005650-199907000-00010.

43 Wennberg JE, Staiger DO, Sharp SM, et al. Observational intensity bias associated with illness adjustment: cross sectional analysis of insurance claims. BMJ 2013;346:f549. doi:10.1136/bmj.f549.

Appendix 1: Supplementary tables Appendix 2: Supplementary figures 